\title{
Metaphors in a Cognitive Aspect
}

\author{
Bibaisha Nurdauletova, Galiya Abdilova, Sholpan Saparbaikyzy \\ Caspian State University of Technologies and Engineering Named after S. Yesenov, Aktau City, The Republic of \\ Kazakhstan \\ Email: doubleg@rambler.ru
}

Received 2 January 2015; accepted 23 January 2015; published 29 January 2015

Copyright (C) 2015 by authors and Scientific Research Publishing Inc.

This work is licensed under the Creative Commons Attribution International License (CC BY).

http://creativecommons.org/licenses/by/4.0/

(c) (i) Open Access

\section{Abstract}

It is known that a metaphor is a poetic language core. At the same time in a spoken language there are many words formed in a metaphorical way. Recently metaphors like cognitive means became the object of research. In his article, metaphor is considered as a discourse means, acquainting us with mutual relations between the author and recipient.

\section{Keywords}

Cognitive Aspects, Poetic Metaphors, A Symbol, A Stereotype, Anthropocentrism, Thinking Tool, Addressee, A Discourse, Addresser

\section{Introduction}

The secret of metaphors in a language was reflected in the researches of prominent thinkers first Aristotle, Russo, Hegel and further to E. Kassirer and H. Ortega y Gasset. The aspiration to understand the nature of metaphors recently came out of the scope of Philology (oratory, stylistics, and literary critique) and it began to manifest itself in the research aimed at studying cognition and thinking, and also in researches of artificial intelligence. Consideration of metaphors on different discourse (scientific, publisistic, poetic) levels generates versatile ideas of researchers concerning the use of metaphors. Undoubtedly, noncoincidencein such views is born on the basis of a metaphor nature and especially its use in language. For example, some scientists say that the metaphor does not correspond to the practical language.

\section{Metaphors in a Cognitive Aspect}

According to Thomas Hobbes, primarily speech is a means of conveying thoughts and passing knowledge, in this function of a speech the use of a word with its direct meaning is handy and easy [1]. The use of metaphors and words with figurative meaning in speech is "wandering in nonsense without beginning and end.” Philosophers and scientists of the Romantic trend, on the contrary, believed that a metaphor is not simply a means of 
conveying thoughts, but one of the ways of intellection. Nietzsche considered that between the object and subject there is only an aesthetic relationship expressed through metaphors, therefore in his reasoning cognition itself is metaphorical. E. Kassirer regarded the basis of the mythological notion of being in connecttion with metaphors. He divided the mental function of aperson's thinking into the metaphorical (mythical and poetic) and discursivelogical. According to him, metaphorical cognition shows qualitative parameters of cognition in comparison with discursive logical one [2].

\subsection{Metaphor and Symbol}

In order to determine the role of metaphors in poetry, many researchers compared it with other semiotic concepts (symbol, metonymy, metamorphosis). By its imagery, allegory, figurative meaning metaphor is similar to a symbol. Therefore, the notions of metaphoric image and symbolic image are used with some literary critics as synonymous concepts. Similar to image, a metaphor as well as symbol appear spontaneously without influence of a man. Because of this nature, they are more inclined to the object of understanding than to the object of concept. Speech signs are characterized by communicative and pragmatic properties. By means of signs one can store a variety of information and exchange information. But many researchers believe that the information cannot be transmitted via symbols and metaphors, and therefore they cannot be a means of communication.

In addition to the above mentioned features, connecting together a metaphor and symbol, there are also some differences. A metaphor is characterized by its predicative position, so its nature is focused on the meaning, and possibly implementing it into the lexical stock of a language. A symbol is not used in the predication, it is more a form than meaning. A metaphor is“not asking to be on the paper”, while symbol "strives” to be a graphic image. In metaphor two subjects are compared (in the lines “Men aqbauyr ker zhorga, ademi basqan ayagyn” words a poet and ker zhorga are used as a comparison. In the lines "Bazaar ketip basymnan” the end of interesting and happy moments is shown with the metaphorical phrase, in other words it can be expressed by bazardyn tarqauy). There are cases when the figurative meaning turns into significant one and it is included into the dictionary as a separate word. For example, in the Kazakh language the word asqazan means a human organ (stomach), its literal translation is "food digesting pot". This word is a metaphor which became a significant word. Here two subjects are compared: a kitchen utensil in which the food is prepared and human organ in which the food is digested.

Symbols do not have dualsubjectivity; there exists not comparison, but conceptual allegory. (In the lines “Qayyrsyz osken Qarynbay, Ulgisi kalgan saranga” Karynbay is a symbol of miserliness). If the semantic need necessitates the conversion of the image into a metaphor, then its transformation into a symbol is mainly affected by extra-linguistic factors, it means that the decisive factor in transforming the image into a symbol are the functions performed by a single person in religious and cultural unity and ideological harmony of the society, state and humanity in general.

\subsection{Anthropocentricity of Metaphor}

Language through its values and its associating system attaches national-cultural character to the conceptual model of the world. However, it conveys anthropocentric concept, reflected in human perception by universal human concepts, value of the world, symbols and standards. With these concepts there were formed evaluating concepts of specific language stereotypes. For example, in Kazakh language hardness is conveyed by a metaphor a stone, bondage by a metaphor a slave, cunning is associated with a fox.

By its nature a metaphor is similar to word formation, but in comparison with it a metaphor is more complicated, it corrects a certain model of the new meaning formation, which is difficult to observe, it performes lingua creative function in language. Description of the synthesis process of turning into a metaphor is associated with the target activity of a metaphor generating subject. This function is involved not only for naming, supplementing conceptual lacunas, but also for education through the metaphor of a pragmatic influence on the the recipient. In its turn, the recipient factor calls for reckoning with the concepts in the way of selection of signs related to the realias, creating a metaphor. Only after comparing previously familiar realias and realias that have got a new name in the mechanism of metaphor generating, and making a meaningful synthesis in different logical dimensions based on the formation of new word combinations anthropocentric features are elicited.

One of the ways of metaphor formation is sifting by a person new phenomena through the knowledge, collected during the life practice and eventually turning them into stereotypes, models, symbolic names of different 
types (scientific, common, mythological). For example, for the formation of such phraseological units as “iygynan zhuk tusti" (load fell from shoulders) meaning relief, "sausagyn shoshaytu” (to point the finger) as mocking, "yensesi tusti" (to lose heart) asto be sad, the basis is common for the speaker in Kazakh society linguocultural stereotypical notions.

On these examples, we were convinced that E. Bartminsky’s naming phraseological units as "national stereotypes" is notrandom. V. N. Teliya notes that the concept on the function of metaphor in shaping the nominative meaning becomes popular among the linguists. In the studies of M. Black metaphorization is finding new reserves of knowledge about the world and their transformation into the vocabulary of the language.

There are two kinds of metaphors: linguistic and and poetic.“...linguistic metaphor is a ready lexis element, it is not necessary to create, "do" such metaphor, it is taken ready and then used in speech, often one is not even aware that the familiar words have a figurative sense.” Due to the fact that the ways of metaphor formation (similarity with different objects, holding associations with similar concepts, imagery) are the same, such division of metaphors may seem inappropriate. However, in our opinion, the basis of a linguistic metaphor lies in language genesis nature.Linguistic metaphors are so rooted in the conversational speech that sometimes semantic relationship between the objects transferred through a particular metaphor becomes dim.

Poetic metaphor is the aesthetic, emotional, emotive phenomenon generated by oratorical, poetic talent. The way of its formation is considered to be individual, imaginative artistic structure, formed by weighing artistic taste and learning universal and national world cognition.

V. N. Telia investigating functional and nominative role of metaphors identifies the following types of metaphors: identifying or indicative metaphor based on similarity between signifier and signified [3]; conceptual metaphor that similizes heterogeneous and identifies similar properties to synthesize a new concept [4]; figurative metaphor, which focuses on an artistic effect on the recipient, causing him to have some value attitude towards the world, it can be determined in a range of categories of beautiful or ugly [4]; evaluative metaphor which is realized in the value judgment on the properties of an object; emotive colored metaphor (connotation is present in it, macrocomponent of a meaning, which includes, along with figurative-associative meaning, emotive modality and stylistic markedness) [3].

As examples of indicative metaphors there can be as follows: tumsyk-a nose (kemenin tumsyghy-a nose (stern) of a ship, zherdin tumsygy - a nose of the earth), koz-an eye (terezenin kozi-eye of the windowwindow glass), kabyrga (a rib) — a wall (uydin kabyrgasy — the wall of the house).

The metaphors adamnyn cozy (an eye of a man) — terezenin cozy (an eye of a window, kustyn tumsygy (a nose of a bird) - kemenin tumsygy (a nose of a ship (stern), adamnyn kabyrgasy (a rib of a man) —uydin kabyrgasy (a wall of a house) are similar phenomena. These examples illustrate the way of metaphor formation by similarity of meanings.

In conceptual metaphors of zhyrau like kanymen daret alu (wash oneself with blood)—sumen daret alu (wash oneself with water) a new concept appears by similizing and identifying heterogeneous andsimilar properties.

In the works of José Ortega y Gasset a metaphor is not only seen as a means of formation of new titles, but also as a means of thinking: “... metaphor is not only a name, but also thinking. Herein lies the second and deeper essential function of a metaphor. We need metaphor not only for the object to become available to our thoughts. Metaphor is not only a means of expression and is also an important tool of thinking.” [5].

In the formation of metaphors to a generated new meaning a stock of existing information previously stored in the "code of memory" or linguistic human society is included. In order to understand the nature of a metaphor George Armitage Miller proposed the idea of “apperception”. In the process of getting acquainted with the text the recipient looks for information known to him before, related to the content of information or an idea proposed by the addressee (author). In other words, the image is updated in the memory. Through the information found in the fund of knowledge there is constructed the "semantic model", corresponding to new information. As relevant new information is to previous fund of data, so facilitated the formation of semantic model will be. For example:

Agyzayyn arnasyn, Keudemde asyl Bulak bar.

(I will spill the channel, In my breast there is a precious spring).

In order to understand that a precious spring is a "song", it is necessary to base all of our knowledge on a spring. For the purpose the "sphere of knowledge”, "selfcognition” associated with a spring are involved. Based on the following knowledge about a spring, A spring is a perennial water source fighting from under the earth. All live satisfy thirst with spring water, find rest in a shadow of the trees growing near a spring. A spring is a 
source, principal of life” a person forms a new "semantic model” a word, a song, which as well as a spring fights from a man's chest and pleases others.

The idea of apperception by George A. Miller is that though a "metaphor" is far from the truth of real life, nevertheless we include all possible images related to it [6]. For example, let us try to form a "semantic model" corresponding to the metaphorical combination in Kazakhpoetic language "kanymen daret alu", which means "to wash with blood". According to the religious notion "ablutionis one of the five duties of a Muslim" meaning "to wash, purify." The concept of "to wash with blood" explains directly through the frame "to be sheit" the cognitive structure of the concept "death". "The scope of knowledge" related to sheit is coloured by religious notion. A man who dies for the sake of fairness, humanity with the aim to protect his people, land, religion is considered to be a sheit. A sheit is also a favorite slave of Allah. Sheits go to paradise.

In the poetic combination "shaytannyn kokirekte askhanasy", which literally means "a chest refectory for the devil", the main dominant meaning is taken and connotated from denotative meanings of the words devil, chest, meal. Devil in religious terms is the enemy of a man, bringing him down from a true way, in the mythological concept it is a subject of chaos world, the image disturbing a man. Chest is a physiological concept of "a motor" of human life, the body, which protects other vital organs such as a heart, lungs; and in the poetic use: the human heart, and if it stops beating, then together with it life will stop too. It is a human thoughts regulator (kokiregine toqu); a refectory is the place of eating. Three different conceptual structures (frames), which are not connected with each other and via associations they form a new concept. The connotative meaning of the word combination is as follows: "The devil derives strength from bad thoughts, bad intentions of a man which are in his chest.” The philosophical conclusion contains the following: 1) A devil is the main source of human life, he settles down in the heart, therefore it is the most dangerous, most powerful enemy. 2) Everyone through bad thoughts in his chest gives strength to the devil.

Talay zhiyn korgenmin, Sozden shashu bergenmin, Soz kausari bulaqtan Kandyrayyn sholindi.

Creation of significant associations of the concepts of "word" (soz)—showeringgifts, "song" (olen)—a spring is relevant not to a common man but poetic thinking person. But "shashu" (showering gifts) means showering gifts in the form of money and sweets at feasts, holidays, on the joyous occasion; "Bulak" (a spring) is fighting from under the earth perennial crystal clear water. These two words compile a certain concept inherent to Kazakh people. The following word combinations are considered to be frames-scenarios, compiled by the poet himself: "Sozden shashu beru" (literally to shower with gifts of words), "Soz kausarynan sholin қandyru" (literally to satisfy thirst from a verbal spring).

Drawing up metaphor as a means of thinking reflects the role of above mentioned linguistic phenomena in conceptual image of a man's (language user) world cognition. Through using in research the metaphor nature, theory of cognitive structures-frames, scripts, mental schemes in the minds we can presume the basis of cognitive metaphor theory.

According to W. Humboldt words are concepts expressing our opinion on the subjects, concept formation is an internal process. As for the motivation of language elements, they are determined by the internal laws of language, its entire structure. The subject of linguistic research should not be lexical composition of a word but its social environment [7].

\subsection{Metaphor as a Carrier of National Culture}

Earl R. MacCormack in his book "A Cognitive Theory of Metaphor" indicates to the following main features of metaphor: a metaphor in its external structure complicates our understanding of the world and is the leading cognitive process in the creation of new hypotheses in its inner meaning, carries outa unifying role between thinking and human culture. New metaphors enrich our language, expand our world cognition. With the help of metaphorical denotations our vocabulary is supplemented. At the same time, metaphors, changing vocabulary carry out cultural evolution. It is also certain that metaphors affect our character and with that they also run biological evolution. To summarize, we can say that metaphor is a cognitive process (it means something, forms a new concept), and at the same time cultural process (it enriches vocabulary) [8].

In addition, the semantic substance of poetic metaphor is context. In our opinion, metaphorical meaning is specifically revealed, the effect is not in a single word, it is within the whole context meaning.

In scientific discourse proposed by V. N. Teliya metaphor is characterized as an indicator of the human factor in language. In the historical development of language national cultural and spiritual wealth, formed by a lan- 
guage group is preserved and find sits extention in metaphors. At the same time, a metaphor (as well as other stylistic devices) is considered to be the association of a real world, perceived via consciousness by the similarity and unity of heterogeneous values through the association, physical perception of a real world and the perception of the invisible world (the world of ideas, aspirations), transition of abstract inventions of the world into specific cognition [9].

A language through its values and system of associations attaches national and cultural image to the conceptual model of the world. At the same time, it is characterized by anthropocentric understanding, measured by human concepts, world extent, symbols, and standards of human perception. Evaluation concepts of specific stereotypes are formed there through. For example severity, ruthlessness are transmitted through using a metaphor stone, dependence as a slave, cunning is associated with a fox.

By its nature, a metaphor is similar to the word-formation, but in comparison it improves a certain model of new meaning forming, not following measurements, implements lingua creative function in the language. Peculiarities of metaphor process synthesizing depend on the target function of the metaphor forming subject. This function is not only nominative, replenishing conceptual lacunas, at the same time it participates through metaphor in the formation of a pragmatic influence on the recipient. In its turn the destination factor obliges the creator of the metaphor in the process of selection to take into consideration the concepts related to the realias. Only after comparing the realias formerly known in the mechanism of metaphor forming with the realias which got new names, only after significant synthesis in different logical measurements, peculiarities of new words creation mostly are elicited by the property of human dimension. A man expressing his thoughts about new phenomena through knowledge collected during the life experience eventually transmits them into stereotypes, models, symbolic names in different images of the world (scientific, common, mythical). It is one of the metaphor forming ways (for instance, the reason for implementing in the language the word "balmuzdaq" (ice cream, the literal translation from the Kazakh is honey ice) is physical and sensitive perception of the thing by thehuman). As it was shown by V. N. Teliya, the concept of the nominative meaning function in the formation of metaphor recently became known among the linguists. In the M. Black's studies metaphorization serves to replenishvocabulary and the fund of new knowledge about the world [9].

According to the view of J. Lakoff and Mark Johnson, authors of the book "Metaphors We Live By" [10], metaphor does not belong only to language, it also belongs to reasoning, how human thought processes are largely metaphorical. "Metaphors as expressions of a natural language are possible precisely because they are metaphors of a human conceptual system". In this book metaphor is considered in the conceptual, cognitive aspect: metaphor is orientation; metaphor is in the empirical basis; metaphor is a cultural value; metaphor is otologic entity representation of essence and substance [10].

A poetic metaphor is an aesthetic, emotional linguistic phenomenon, leaving a lasting impression, and emerging as a result of the poetic art of eloquence.

The basis of its formation is an individual, imaginative artistic structure created on the basis of universal human and national perception and cognition of the world picture. In the poetry of zhyrau there also are found common linguistic metaphors, metaphors of zhyrau, traditional poetic metaphors, created by an author, however, metaphors, reflecting individual knowledge and vision of the world by the akin-poet himself.

\section{Conclusions}

In cognitive paradigm, metaphor is a means of expressing linguistic picture of the world. In this study, metaphors in zhyrau are considered through characterization of conceptual understanding of the world in the context of the addressee - text-addresser. Since on the language of zhyr, metaphors on the one hand are used to make a text colorful, aesthetic, emotional, on the other hand it influences the interaction between a listener and speaker. The more real and pleasant to the perception and ears are, the artistic image of the world in metaphors is. The more spellbinding and impressive it is on the listener.

Along with this in the text of zhyr, metaphors perform pragmatic role.

The use of metaphor requires the author's (addresser's) ability to express and formulate it properly, impress the addressee, taking into account his national outlook. And thus the author of the zhyrau text should be a witty, eloquent and deep thinking person.

\section{References}

[1] Thomas Hobbes (1990) Theory of Metaphor. Progress, Moscow, 511. 
[2] Cassirer, E. (1990) The Power of Metaphor. Progress, Moscow, 511.

[3] Arutyunova, N.D. (1990) Metaphor and Discourse. Moscow, 511.

[4] Teliya, V.N. (1988) Metaphor in Language and Text. Nauka, Moscow.

[5] José Ortega y Gasset (1990) Two Great Metaphors. Progress, Moscow, 511.

[6] Miller, J. (1990) Images and Models, Similes and Metaphors. Theory of Metaphor, Progress, Moscow, 511.

[7] Aitova, N.N. (2005) Kazakh tilindegi tur-tus ataularynyn kognitivtik semantikasy. TOO “Arys”, Almaty, 126.

[8] MacCormac, E.R. (1990) Cognitive Theory of Metaphor. Progress, Moscow, 511.

[9] Teliya, V.N. (1988) Metaphorization and Its Role in Creating the Linguistic World. The Role of the Human Factor in the Language: Language and World View. Nauka, Moscow, 212.

[10] GeorgeLakoff and Mark Johnson (2004) Metaphors We Live by. Editorial URSS, Moscow, 256. 
Scientific Research Publishing (SCIRP) is one of the largest Open Access journal publishers. It is currently publishing more than 200 open access, online, peer-reviewed journals covering a wide range of academic disciplines. SCIRP serves the worldwide academic communities and contributes to the progress and application of science with its publication.

Other selected journals from SCIRP are listed as below. Submit your manuscript to us via either submit@scirp.org or Online Submission Portal.
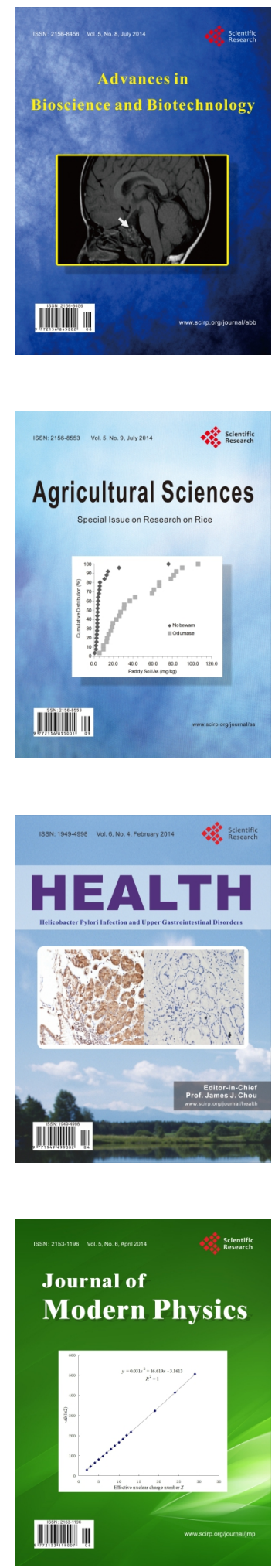
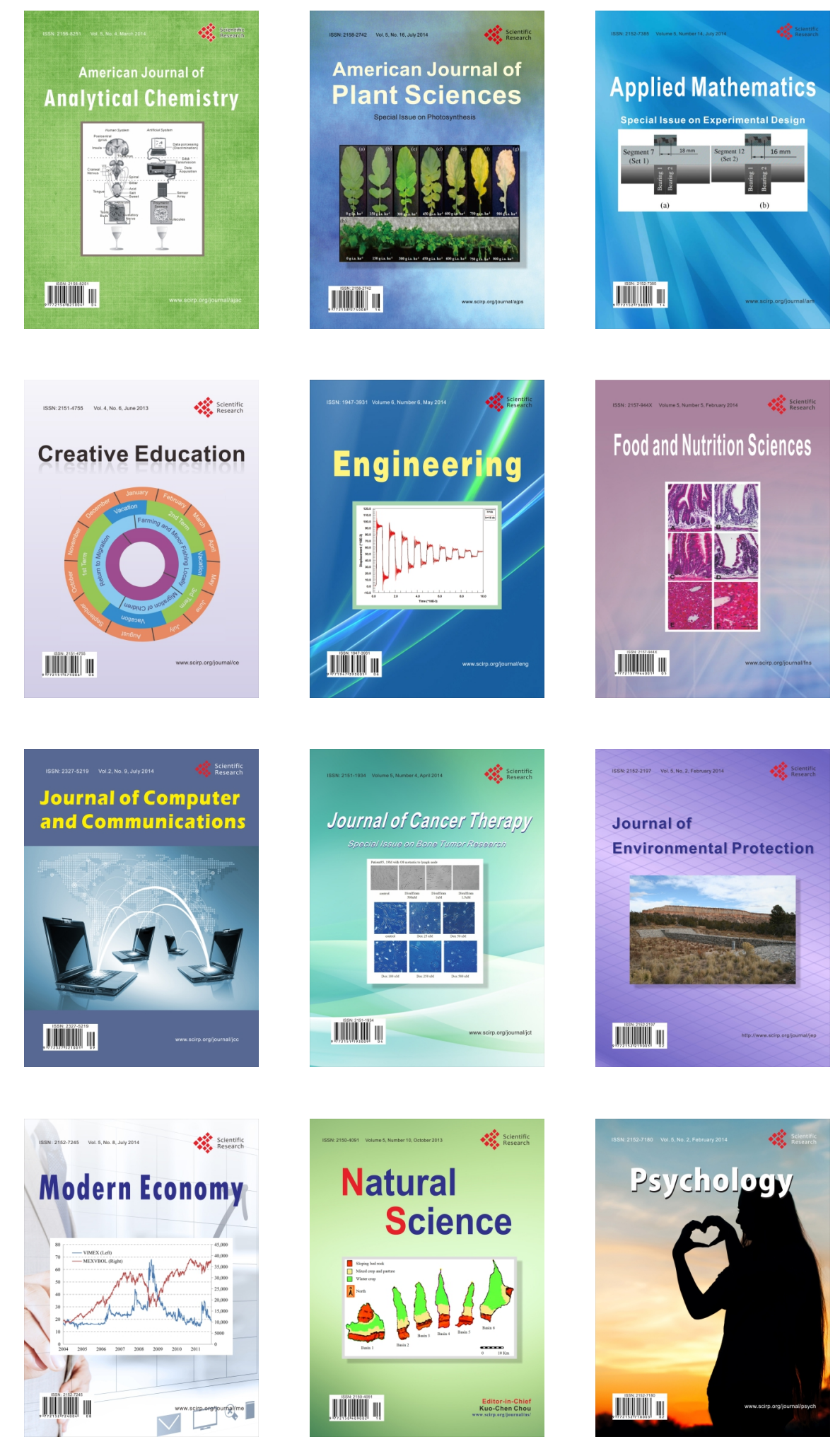